\title{
Rural-Urban Migration and Experience of Childhood Abuse in the Young Thai Population
}

\author{
Tawanchai Jirapramukpitak • Melanie Abas • \\ Trudy Harpham • Martin Prince
}

Published online: 4 September 2011

(C) The Author(s) 2011. This article is published with open access at Springerlink.com

\begin{abstract}
Evidence suggests that certain migrant populations are at increased risk of abusive behaviors. It is unclear whether this may also apply to Thai rural-urban migrants, who may experience higher levels of psychosocial adversities than the population at large. The study aims to examine the association between migration status and the history of childhood sexual, physical, and emotional abuse among young Thai people in an urban community. A population-based cross-sectional survey was conducted in Northern Bangkok on a representative sample of 1052 young residents, aged 16-25 years. Data were obtained concerning: 1) exposures - migration (defined as an occasion when a young person, born in a more rural area moves for the first time into Greater Bangkok) and age at migration. 2) outcomes - child abuse experiences were assessed with an anonymous self report adapted from the Conflict Tactics Scales (CTS). There were 8.4\%. 16.6\% and $56.0 \%$ reporting sexual, physical, and emotional abuse, respectively. Forty six percent of adolescents had migrated
\end{abstract}

T. Jirapramukpitak $(\bowtie)$

Department of Psychiatry, Thammasat University,

Paholyothin Road,

Klong Luang, Pathumthani,

Thailand 12120

e-mail: tawanchaij@gmail.com

T. Jirapramukpitak $\cdot$ M. Abas $\cdot$ M. Prince

Section of Epidemiology, Institute of Psychiatry,

DeCrespigny Park,

London, UK SE5 8AF

T. Harpham

Department of Urban, Environment and Leisure Studies,

London South Bank University,

103 Borough Road,

London, UK SE1 0AA from rural areas to Bangkok, mostly independently at the age of 15 or after to seek work. Although there were trends towards higher prevalences of the three categories of abuse among early migrants, who moved to Bangkok before the age of 15 , being early migrants was independently associated with experiences of physical abuse (OR $1.995 \%$ CI 1.1-3.2) and emotional abuse (OR 2.0, 95\%CI 1.3-3.0) only. Our results suggest that rural-urban migration at an early age may place children at higher risk of physical and emotional abuse. This may have policy implications for the prevention of childhood abuse particularly among young people on the move.

Keywords Child abuse · Transients and migrants · Young adult $\cdot$ Thailand

Recognition of the significance of child abuse as a global public health concern and its devastating impact has increased (WHO 2002). In line with the report, violation of children's right, such as child prostitution and labor in Thailand, is widespread (Berger and Glind 1999). The magnitude of child abuse experiences has also been demonstrated by a number of epidemiological studies (Isaranurug et al. 2001, 2002; Isaranurug et al. 2002; Jirapramukpitak et al. 2005).

Child abuse has various definitions, which have never been formally operationalized (Cicchetti and Toth 1995). However, the International Society for the Prevention of Child Abuse and Neglect recently compared definitions of abuse from 58 countries and found commonalities in what was considered abusive (Bross et al. 2000). It is agreed that child abuse or maltreatment constitutes many forms that result in actual or potential harm to the child's health, survival, development or dignity in the context of a relationship of responsibility, trust, or power (WHO 
1999). The present study follows the WHO guideline, but focuses primarily on three types of abuse, namely sexual, physical, and emotional abuse. Sexual abuse is defined as those acts where someone older uses a child for gratification. Physical abuse of a child is defined as those acts of commission by an adult member in the household that cause actual physical harm or have the potential for harm, except some widely-accepted forms of corporal punishment (Baron 2005). Emotional abuse in the present study includes acts that have an adverse effect on the emotional health and development of a child.

Child abuse is the result of the complex interplay of individual, relationship, social, cultural, and environmental factors (Belsky 1993). A range of society-level factors are considered to have important influences on the ability of parents to care for children and on the resources available to families. Among these factors is migration which can adversely affect family units, a source of protection from violence for children (Pinheiro 2006). In developing countries rural-urban migration is a main contributor to urbanization and has dramatically increased over recent decades (Guest 2003). The stressful conditions of Thai rural urban migrant was well-documented (Chamrathrithirong and Dejong 1999) and psychosocial adjustment in the face of moving may be particularly difficult for migrant families.

Parental occupation with the demands of a new environment have the potential to erode the quality of parent-child relationships, lessen parental supervision, or significantly reduce parent-child contact (Sampson and Laub 1995). In addition, moving into cities may lead to a breakdown of social support networks and social control over the behaviors of migrant parents. Child migrants, therefore, lack the protection from other family members or long-standing neighbors available in the rural communities, leaving child migrants exposed to greater risks. Adult migrants, on the other hand, are largely motivated by nonavailability of work or education at the migrants' area of origin. However, they could also be forced to migrate by high levels of stress and social hardship, as well as by being subject to various forms of abuse at home. Whether there is a difference in risk for abuse between those moving at different stages in life remains unclear.

To date there is insufficient evidence to support any notion of the relationship between history of child maltreatment and rural-urban migration. Available evidence comes from studies on migration and immigration of ethnic minorities in the United States. These studies were primarily concerned with children of Latino families (Dettlaff et al. 2009) and of migrant farm workers (Alvarez et al. 1988; Larson et al. 1987, 1990), who were more at risk of being maltreated than other children. There was also concern over the migrant farm worker populations and their increased potential of abusive behaviors against their spouses or partners (Kugel et al. 2009).

The context and pattern of migration and immigration of ethnic populations in the U.S. is very different and unlikely to be generalizable to rural-urban migration of Thai people. This is because, not only are these relocating families under potentially higher stress and pressure from certain psychosocial difficulties, such as fear, loss of previously established support systems, social isolation and uncertainty about the future, but also under additional pressure from acculturation (Earner 2007; Segal and Mayadas 2005), as parents and children experience changing cultural contexts.

The main objectives of this study were to describe the association of migration at a particular critical age period and child abuse experiences. We hypothesized that those who moved into Bangkok would be more likely to have experienced childhood abuse than the natives of Bangkok.

\section{Method}

A cross-sectional survey was conducted in a selected catchment area, called Rangsit District, located adjacent to the north border of Bangkok. The area has seen a rapid increase in population over the past decades and been integrated into the metropolis (Nathalang 2000). The population growth pattern of Rangsit Area represents a distinct form of urbanization, which has risen in several countries of Southeast Asia, popularly known as the desakota or extended metropolitan region (McGee 1991). Rangsit is at the gateway to the upper part of Central Thailand, connecting it with the northern and the northeastern provinces. The huge flow of raw materials for commercial and industrial purposes brought down to Bangkok through this corridor has made Rangsit a natural focus for in-migration for people from all walks of life (Nathalang 2000).

A sample of 1052 eligible residents, aged $16-25$ years living in the district was recruited. There were no exclusion criteria. All people in the age range were included. We first enumerated the catchment area population by knocking on the doors of all households, identifying young persons aged 16 to 25 . In the event that there was more than one eligible resident in a given household, we selected one at random to be interviewed using Kish grid method (Kish 1965). If the selected eligible person was not at home at the time of the first approach for interview, substitution was not permitted. We ensured that repeated visits on at least three occasions were made to interview the selected person so as to reduce non-response. Six interviewers were recruited and trained by the principal investigator. The main survey instrument consisted of two parts: an interviewer administered questionnaire and a self-administered questionnaire. This self- 
report questionnaire was used to collect sensitive information (i.e., child abuse experiences). They arranged to interview the selected individuals in their own homes during October 2003-April 2004.

The study protocol was approved by the Institutional Review Boards. Participation to the study was voluntary and based on written informed consent from the participants. Careful attention was given to the risk of distress in participants. Participants were provided with a list of institutions and contact workers for specialized help.

\section{Childhood Abuse Experiences}

History of childhood abuse was screened with anonymous self-administered questionnaires. The respondent was asked to complete the questionnaires in private, put them in a sealed envelope, and give it back to the interviewer on-site to ensure confidentiality. It was feasible because the illiteracy rates among Thai adults, aged 15 and above are very low, 2.8\% for men and $6.1 \%$ for women (United Nations Statistics Division 2000). The questionnaires covered three categories of child abuse (emotional, physi$\mathrm{cal}$, and sexual abuse). The questions were adapted from the Conflict Tactic Scale (CTS) (Straus 1979). The CTS has been used for measuring child abuse in several studies with some modifications (Caliso and Milner 1992; Felitti et al. 1998; Straus and Hamby 1997; Straus et al. 1998). The CTS items were translated and then adapted based on focus group discussions with local key informants, which provided guidelines on domains (i.e., emotional, physical and sexual abuse) to be included in the questionnaire and items to be included in each domain. The age of 16 or under was agreed as the critical childhood period of enquiry regarding abusive experiences occurred. The items used to define abusive experiences were:

Emotional abuse: "How often did a parent or other adults in the household (1) scold or insult you in a way that made you feel bad or inferior; (2) yell or scream at you; (3) say something or make sarcastic remarks that made you feel guilty or hurt; (4) humiliate you in public or in front of others?"

Physical abuse: "How often did a parent or other adults in the household (1) actually push, grab, or shove you?; (2) throw something at you?; (3) slap you on the face, ear or head?; (4) hit you so hard that you had marks or bruises?; (5) kick, punch, or hit you with a fist?; (6) threaten to hurt you or actually hurt you with a gun, knife, or other weapon?"

Exposures to these emotional or physical abusive experiences were regarded as present if the respondent reported they had sometimes, often or very often experienced these events before the age of 16 . However, those who were subject to the acts of severe or very severe degree (physical abuse item 6) only once or more times were regarded as experiencing physical abuse.

Sexual abuse was considered present if the respondent reported at least one of the following sexual abuse events before the age of 16 with a person 5 or more years older, with or without consent: The stem item was "Did an adult or older relative, parent, family friend, older friend, acquaintance or stranger ever: (1) touch or fondle your body in a sexual way?; (2) have you touch their body in a sexual way?; (3) attempt to have any type of sexual intercourse (oral, anal, or vaginal) with you?; (4) actually have any type of sexual intercourse (oral, anal, or vaginal) with you?" The last item was regarded as penetrative sexual abuse.

\section{Migration History}

Migration status was obtained using the approach developed by Institute of Population and Social Research (IPSR) at Mahidol University (Yoddumneun-Attig 2002). Migration was generally defined as a change in usual residence, which was simply that address where the respondent had lived for 1 month or more at the time of the interview. We ascertained lifetime history of migration, including the places of birth of the respondent, the destinations for all moves, the duration of each stay, the reason for migration and the age at migration. However, the significant migration event was defined as the occasion when a young person, born in a more rural area moved for the first time into Bangkok Metropolitan Region (BMR). The age of 15 was used as a critical-age period as Thai children under this age are more likely to move with their parents or adults, as opposed to older children, who by Thai law are able to get a paid job and perform certain official acts (BIA 2006). They are, therefore, able to move on their own and seek work.

The choice of variables for confounders was based mostly on sociodemographic factors including: respondents' sex, age, level of education, and a proxy variable for social class, measured with head of household's years of education.

Analysis

Statistical analyses were performed with STATA version 8 . In bivariate analysis, we estimated the prevalence of migrants and odds ratios for their association with child abuse experience. In multivariate analysis (logistic regression) we estimated the independent associations of the three migratory statuses (non-migrant, migrants moving before the age of 15 , migrants moving at the age of 15 or after) with each of the three child abuse categories (sexual, physical, and emotional abuse) having controlled for the 
potential confounding effects of other variables including sex, the respondent's and head of household's education. The non-migrant group was the reference category in the logistic models. All of the prevalence estimates, bivariate and multivariate analyses were weighted back, using STATA svy commands, to take account of the total number of eligible people in the household.

\section{Results}

\section{Participant Characteristics}

In all, 3,469 of the occupied households were identified. A total of 1,080 households contained at least one eligible resident. Twenty-five eligible people $(2.3 \%)$ could not be contacted and 3 persons $(0.3 \%)$ refused to participate, leaving a total of 1,052 eligible persons successfully completed interviews. The overall proportion responding was therefore $97.4 \%$. In the sample two people were born overseas. They could not be classified clearly according to the predefined migrant status and hence were excluded from the analyses, which involve migration variables. Using the definition of migration, 454 persons $(46.3 \%$, 95\%CI $42.8-49.7)$ were rural-urban migrants, $13.4 \%$ moving from more rural areas into Bangkok Metropolitan Region (BMR) before the age of 15 (early migrants) and $32.9 \%$ moved into BMR at the age of 15 or older (late migrants).

The sociodemographic characteristics of the non-migrant, early migrant and late migrant groups are compared in Table 1. Late migrants were more likely to be older than early migrants and non-migrants. There was no difference in gender composition between the three groups. Late migrants were much more likely to be married than were early migrants and non-migrants. Early and late migrants were less well-educated than their non-migrant peers, and more likely to be working. Late migrants were more likely to be in a lower social position than early migrants and non-migrants, assessed by head of household education level.

Among the migrants, 213 (51.4\%) had moved to find work, 67 (12.6\%) for further study, 169 (34.7\%) for family reasons, and 7 (1.3\%) for other reasons. Of those who had moved for family reasons, $46(31.4 \%)$, all women, had accompanied their husband, $113(62.8 \%)$ had moved with their parents and ten $(5.7 \%)$ moved with a relative. Most of the migrants moved only once $(67.9 \%)$. Only $11.2 \%$ of the migrants had moved three times or more. Most of the moves had been with family members. Only $11 \%$ had moved without their family at some stage in life.

There was a very strong association between age at time of migration and reason cited for migration $(F 24.19$, $p<0.0001)$. The large majority of those migrating at the age of 15 or older moved to find work (64\%). Occasionally they migrated for further education (12.0\%), or to accompany their families (12.4\%). For those migrating under the age of 15 , predominately they moved for family reasons $(55.5 \%)$. Relatively few had moved primarily for work $(20.7 \%)$ or education $(14.3 \%)$.

\section{Abuse Experience}

In all, $59.8 \%(95 \%$ CI $56.4-63.1)$ of the weighted sample reported experiencing some form of abuse during childhood, with sexual abuse reported in $8.4 \%$, physical abuse $16.6 \%$ and emotional abuse $56.0 \%$. Non-penetrative sexual abuse makes up $7.6 \%$ and penetrative sexual abuse $3.8 \%$. Physical and emotional abuse was all at the hand of adults living in the same household, but older friends accounted for the majority of instances of sexual abuse (52.9\% of all sexual abuse cases).

\section{Correlates of Childhood Abuse}

There were no consistencies in the associations of any potential confounders with each of the three types of abuse. Being older was associated with a higher prevalence of emotional abuse (OR 0.7 95\%CI 0.5-0.9), whereas poor education was associated with reporting physical abuse (OR 0.6 95\%CI 0.4-0.8) (Table 2).

\section{Child Abuse Experiences \& Migration}

From Table 3, early migration was significantly associated both with physical $(p=0.02)$ and emotional abuse $(p=0.005)$. The same trend was evident for sexual abuse, but this effect was not statistically significant $(p=0.77)$.

\section{Stratified Analyses by Gender}

There was little evidence to support effect modification by gender to any consistent, coherent or statistically significant degree. The exception was perhaps physical abuse; the associations between migration (particularly early migration) and physical abuse were stronger in males compared with females (Table 4).

\section{Multivariate Analyses (Controlling for Confounders)}

Logistic regression models were developed to test the effect of migration on the three child abuse outcomes, adjusting for all of the relevant potential confounders (Table 5) including age, gender, and education status, and head of household's educational level. The logistic regression model shows that after controlling for all the confounders, early migration remains significantly associated with physical (OR1.9 95\%CI 1.1-3.2) and emotional abuse (OR2.0 95\%CI 1.3-3.0). 
Table 1 Results of univariate analysis of migration and sociodemographic factors

\begin{tabular}{|c|c|c|c|c|c|}
\hline \multirow[t]{3}{*}{ Demographic variables } & \multicolumn{3}{|l|}{ Type of Migration } & \multirow[t]{3}{*}{$F$} & \multirow[t]{3}{*}{$P$} \\
\hline & \multirow{2}{*}{$\begin{array}{l}\text { Non-migrant }(\%) \\
N=596\end{array}$} & \multicolumn{2}{|c|}{ Migrant (\%) } & & \\
\hline & & $\begin{array}{l}\text { Early } \\
N=141\end{array}$ & $\begin{array}{l}\text { Late } \\
N=313\end{array}$ & & \\
\hline \multicolumn{6}{|l|}{ Age } \\
\hline$-16-19$ & 42.9 & 51.6 & 31.8 & \multirow[t]{2}{*}{7.20} & \multirow[t]{2}{*}{0.0008} \\
\hline$-20-25$ & 57.1 & 48.4 & 68.2 & & \\
\hline \multicolumn{6}{|l|}{ Sex } \\
\hline - Male & 45.4 & 45.2 & 48.3 & \multirow[t]{2}{*}{0.31} & \multirow[t]{2}{*}{0.73} \\
\hline - Female & 54.6 & 54.8 & 51.7 & & \\
\hline \multicolumn{6}{|l|}{ Qualification } \\
\hline - No qualification & 0.9 & 2.3 & 0.6 & \multirow[t]{6}{*}{3.16} & \multirow[t]{6}{*}{0.0005} \\
\hline - Primary (6 years) & 6.9 & 14.8 & 17.8 & & \\
\hline - Secondary (9 years) & 38.5 & 45.6 & 42.0 & & \\
\hline - Higher secondary (12 years) & 37.4 & 24.0 & 28.3 & & \\
\hline - Higher diploma (14 years) & 7.5 & 5.5 & 4.9 & & \\
\hline - University & 8.8 & 7.8 & 6.6 & & \\
\hline \multicolumn{6}{|l|}{ Head of household's education } \\
\hline - None/little & 3.3 & 8.8 & 1.9 & \multirow[t]{7}{*}{4.68} & \multirow[t]{7}{*}{$<0.0001$} \\
\hline - Primary (4 years) & 33.6 & 41.5 & 39.5 & & \\
\hline - Primary (6 years) & 8.7 & 12.9 & 20.4 & & \\
\hline - Secondary (9 years) & 12.8 & 16.6 & 14.8 & & \\
\hline - Secondary (12 years) & 18.6 & 7.4 & 12.6 & & \\
\hline - Higher diploma (14 years) & 9.7 & 5.5 & 2.8 & & \\
\hline - University & 13.3 & 7.4 & 8.1 & & \\
\hline
\end{tabular}

\section{Discussion}

To our knowledge, this is the first community study to examine the potential impact of rural-urban migration at the defined age period on the three categories of child abuse experience among young people. Our study found that, although there were trends towards higher prevalences of the three types of abuse, rural-urban migration at an early

Table 2 Odds ratios for the associations between the three categories of child abuse and potential confounders

\begin{tabular}{|c|c|c|c|c|c|c|c|}
\hline \multirow[t]{2}{*}{ Variable } & \multirow[t]{2}{*}{$N$} & \multicolumn{2}{|l|}{ Sexual abuse } & \multicolumn{2}{|c|}{ Physical abuse } & \multicolumn{2}{|c|}{ Emotional abuse } \\
\hline & & Prevalence & $\mathrm{OR}(95 \% \mathrm{CI})$ & Prevalence & $\mathrm{OR}(95 \% \mathrm{CI})$ & Prevalence & $\mathrm{OR}(95 \% \mathrm{CI})$ \\
\hline \multicolumn{8}{|l|}{ Age } \\
\hline$-16-19$ & 449 & 9.0 & 1 & 19.5 & 1 & 61.0 & 1 \\
\hline$-20-25$ & 603 & 7.9 & $0.9(0.5-1.5)$ & 14.7 & $0.7(0.5-1.0)$ & 52.6 & $0.7(0.5-0.9)^{*}$ \\
\hline \multicolumn{8}{|l|}{ Sex } \\
\hline - Male & 467 & 10.2 & 1 & 18.9 & 1 & 58.6 & 1 \\
\hline - Female & 585 & 6.7 & $0.6(0.4-1.1)$ & 14.7 & $0.7(0.5-1.1)$ & 53.8 & $0.8(0.6-1.1)$ \\
\hline \multicolumn{8}{|l|}{ Education } \\
\hline - 9 years or less & 558 & 8.3 & 1 & 20.4 & 1 & 59.0 & 1 \\
\hline - $>9$ years & 494 & 8.4 & $1.0(0.6-1.8)$ & 12.5 & $0.6(0.4-0.8)^{*}$ & 52.7 & $0.8(0.6-1.0)$ \\
\hline \multicolumn{8}{|c|}{ Head of household's education } \\
\hline-6 years or less & 539 & 8.3 & 1 & 18.0 & 1 & 58.0 & 1 \\
\hline - >6 years & 513 & 8.4 & $1.0(0.6-1.8)$ & 15.1 & $0.8(0.6-1.2)$ & 53.8 & $0.8(0.6-1.1)$ \\
\hline
\end{tabular}

$* p<0.02$ 
Table 3 The associations between migration status and child abuse experiences

\begin{tabular}{|c|c|c|c|c|c|}
\hline \multirow[t]{3}{*}{ Type of Abuse } & \multicolumn{3}{|l|}{ Type of Migration } & \multirow[t]{3}{*}{$F$} & \multirow[t]{3}{*}{$p$-value } \\
\hline & \multirow{2}{*}{$\begin{array}{l}\text { Non-migrant }(\%) \\
N=596\end{array}$} & \multicolumn{2}{|c|}{ Migrant (\%) } & & \\
\hline & & $\begin{array}{l}\text { Early } \\
N=142\end{array}$ & $\begin{array}{l}\text { Late } \\
N=314\end{array}$ & & \\
\hline \multicolumn{6}{|l|}{ Sexual abuse } \\
\hline - No & 92.2 & 89.9 & 91.4 & 0.25 & 0.77 \\
\hline - Yes & 7.8 & 10.1 & 8.6 & & \\
\hline \multicolumn{6}{|l|}{ Physical abuse } \\
\hline - No & 85.9 & 74.7 & 82.6 & 3.98 & 0.02 \\
\hline - Yes & 14.1 & 25.3 & 17.4 & & \\
\hline \multicolumn{6}{|l|}{ Emotional abuse } \\
\hline - No & 47.0 & 30.3 & 44.7 & 5.30 & 0.005 \\
\hline - Yes & 53.0 & 69.7 & 55.3 & & \\
\hline
\end{tabular}

age increased the risk for physical and emotional abuse only. The risk persisted even after adjustments in the multivariate model. The reason for the increased risk among early migrants remains unclear, however. One possible explanation may lie in the social impact of moving. Geographical mobility may result in high social adversity among migrant parents and their children, which in turn increases the risk for child maltreatment (Bardi and Borgognini-Tarli 2001). The social and financial strain of moving experienced by migrant families may be higher than non-migrant groups and migrants moving on their own without dependants. Thai migrant families are often even more burdened by the need to send remittances back home to support their parents (Chamratrithirong et al. 1995).

No association between migration and sexual abuse may have been due to the fact that sexual abuse reported in the study had been largely committed by someone outside the family and therefore much less likely to be contributed by intra-familial stress. On the other hand, the reason for the gender differential effect of migration on physical abuse was not so clear. Physical punishment may be a more acceptable way of discipline among boys than girls, although generally there was no significant difference in the prevalence of physical abuse between males and females (Table 2). It needs to be interpreted with caution, however, as it was not a primary hypothesis for this investigation.

'Social Isolation' is also among the most frequently cited factors in theoretical and empirical reviews for child abuse (Belsky 1993). 'Social Isolation' theorists argue that parents who maltreat their children as a result of moving, are shut off from community or formal supports, as evidenced by fewer contacts with organizations such as churches and clubs (Elmer and Gregg 1967). Based on such conceptual framework previous studies have used frequency of moving as a proxy measure for the level of social networks and support received by parents - the constructs of 'social isolation'(Coohey 1996). Parents who maltreated their children were thought to move more often and therefore moved further away from potential sources of informal support and resources. Available evidence from previous studies, all in the U.S., has shown that frequent move was

Table 4 Odds ratios for the association between migration and type of abuse, stratified by gender

\begin{tabular}{lllllr}
\hline Type of abuse & Male & Female & Crude odds ratio & Adjusted odds ratio & LR test for interaction \\
\hline Emotional & & & & & \\
- Early migrant & $2.1(1.1-4.1)$ & $2.0(1.1-3.4)$ & $2.0(1.3-3.1)$ & $2.0(1.3-3.1)$ & $1.1(0.8-1.5)$ \\
- Late migrant & $1.3(0.8-2.1)$ & $0.9(0.6-1.4)$ & $1.1(0.8-1.5)$ & 0.50 \\
Physical & & & & & \\
- Early migrant & $4.0(1.9-8.4)$ & $1.0(0.5-2.2)$ & $2.1(1.2-3.5)$ & $2.1(1.2-3.5)$ & 0.01 \\
- Late migrant & $1.7(0.9-3.1)$ & $1.0(0.6-1.7)$ & $1.3(0.9-1.9)$ & $1.3(0.8-1.9)$ & 0.02 \\
Sexual & & & & $1.3(0.7-2.7)$ & 0.24 \\
- Early migrant & $1.2(0.4-3.6)$ & $1.5(0.6-3.8)$ & $1.3(0.7-2.7)$ & $1.1(0.6-2.2)$ & 0.89 \\
- Late migrant & $1.2(0.4-3.2)$ & $1.0(0.4-2.4)$ & $1.1(0.6-2.2)$ & \\
\hline
\end{tabular}


Table 5 The odds ratios following logistic regression for the association between migration status and each of the three types of child abuse, controlling for potential confounders

\begin{tabular}{|c|c|c|c|c|c|c|}
\hline & \multicolumn{2}{|l|}{ Sexual abuse } & \multicolumn{2}{|l|}{ Physical abuse } & \multicolumn{2}{|c|}{ Emotional abuse } \\
\hline & Early migrant & Late migrant & Early migrant & Late migrant & Early migrant & Late migrant \\
\hline Model 1 & $1.3(0.7-2.7)$ & $1.1(0.6-2.3)$ & $2.1(1.3-3.5)$ & $1.3(0.9-1.9)$ & $2.1(1.4-3.2)$ & $1.1(0.8-1.5)$ \\
\hline Model 2 & $1.3(0.6-2.7)$ & $1.1(0.6-2.2)$ & $2.0(1.2-3.4)$ & $1.3(0.9-2.0)$ & $2.0(1.3-3.1)$ & $1.1(0.8-1.5)$ \\
\hline Model 3 & $1.4(0.7-2.9)$ & $1.2(0.6-2.3)$ & $1.9(1.1-3.2)$ & $1.2(0.8-1.9)$ & $2.0(1.3-3.0)$ & $1.1(0.8-1.5)$ \\
\hline
\end{tabular}

Non-migrant status was the reference category

Model 1-Main effect of migration

Model 2-Main effect of migration, controlling for age, sex

Model 3-Main effect of migration, controlling for age, sex, years of education, head of household's education

associated with child abuse. Dong and colleagues (Dong et al. 2005) found that adverse childhood experiences including various types of abuse and neglect were strongly associated with frequent residential mobility. A U.S.-based prospective study (Altemeier et al. 1984) on 1400 expectant mothers found that mothers who had moved more than once per month over past year was correlated with abuse experienced by their children $(r=0.027)$.

An analysis of the data of the present study, not presented here, also points to a close relationship between number of move in the past and experience of childhood physical and emotional abuse. This may suggest that the higher number of moves, regardless of direction, the availability of social support reduces, and, in turn, puts the children at higher risk.

Social isolation theory could also be considered part of a broader approach called social capital. Social capital is defined by the World Bank as 'institutions, relationships, and norms that shape the quality and quantity of a society's social interactions' (World Bank 1998). Social capital is theorized to be a resource available to a family that can help families overcome adversity or prosper economically (Putnam 1995). Low social capital has been demonstrated to be a risk for school dropout, violent crimes, childhood injuries, and family violence (Kawachi et al. 1997; Runyan et al. 1998; Sampson et al. 1997; Soubhi et al. 2004). The migration process may affect community and extended family structures common in rural areas and may lead to a breakdown of family and social support networks, resulting in a decreased social capital. Maltreating parents may have difficulties building up the social ties, which come with more stable residence. In addition, loss of norms of parenting behaviours as well as community oversight, may play a significant role. A recent study in the U.S. suggested that increasing social capital decrease the odds of neglectful parenting, psychologically harsh parenting, and domestic violence but not harsh physical punishment (Zolotor and Runyan 2006). Another study, comparing two communities in Spain and Colombia, indicated that in both cultures abusive parents show lower levels of community integration, participation in community social activities and use of formal and informal organizations than the parents who provide adequate care (Gracia and Musitu 2003).

The study has several limitations. First, the assessment of child abuse history addressed sensitive topics and thus were likely to be under-reported. We tried to minimize this by undertaking extensive efforts to protect the confidentiality of responses by using anonymous self-report questionnaire. We also ensured privacy by interviewing the participants when there were no other adult family members nearby. Second, some other potential confounding factors, such as low socioeconomic status and substance use in the family, which may have increased the risk of maltreatment, were not assessed. Previous studies showed that physically abusive parents were more likely to come from low socioeconomic background (Bardi and Borgognini-Tarli 2001; Hadi 2000; Isaranurug et al. 2001)] and have a history of substance abuse or dependence (Klevens et al. 2000). The contributions of these confounders therefore could not be excluded. In addition, the cross-sectional survey design employed by this study provided uncertainty about the temporal sequence of child abuse exposure and migration. It is also possible that migrants may experience childhood abuse at home in the rural areas and are forced to leave. However, this study was not intended to identify any cause-and-effect relationship between child abuse and migration. Rather, our goals were to quantify the relationship of each of these child abuse categories to migration. A longitudinal study of migration in both rural and urban areas and its effect on child abuse is recommended in order to establish the causal routes.

In summary, the findings suggest the potential link between migration and child abuse among a relatively large sample of young men and women. The association between early migration and childhood abuse need further study 
with potential intervening variables, such as parental stress and social capital. Child abuse experiences among early migrants represents a serious challenge to providing care for these children. Recognition of these potential adverse effects of rural-urban migration may be valuable for preventing childhood trauma that could cause adverse impact from childhood through adulthood. Educators and health care providers need to be made aware of the possibility that child migrants may have unobserved abuse experiences. Understanding the difficulties caused by moving, policy makers should ensure that migrants have as equal rights to state welfare and health services as non-migrants.

Acknowledgments The study was funded by the Wellcome Trust's Health Consequences of Population Changes Scheme, UK (WT 069409). We thank Drs. Sureeporn Punpuing and Bencha Yoddumnoen-Attig (Institute of Population and Social Research, Mahidol University) for their advice and assistance in the collection of data.

Open Access This article is distributed under the terms of the Creative Commons Attribution Noncommercial License which permits any noncommercial use, distribution, and reproduction in any medium, provided the original author(s) and source are credited.

\section{References}

Altemeier, W. A., O'Connor, S., Vietze, P., Sandler, H., \& Sherrod, K. (1984). Prediction of child abuse: a prospective study of feasibility. Child Abuse \& Neglect, 8(4), 393-400.

Alvarez, W. F., Doris, J., \& Larson, O., 3rd. (1988). Children of migrant farm work families are at high risk for maltreatment: New York State study. American Journal of Public Health, 78(8), 934-6.

Bardi, M., \& Borgognini-Tarli, S. M. (2001). A survey on parent-child conflict resolution: intrafamily violence in Italy. Child Abuse \& Neglect, 25(6), 839-53.

Baron, J. H. (2005). Corporal punishment of children in England and the United States: current issues. The Mount Sinai Journal of Medicine, 72, 45-46.

Belsky, J. (1993). Etiology of child maltreatment: a developmentalecological analysis. Psychological Bulletin, 114(3), 413-34.

Berger, H., \& Glind, H. (1999). Children in prostitution, pornography and illicit activities: Thailand: Magnitude of problems and remedies. Bangkok: ILO-IPEC.

BIA. (2006). Thailand Legal Guide. Retrieved 7th February 2006, 2007, from http://www.bia.co.th/.

Bross, D. C., et al. (2000). World perspectives on child abuse: The fourth international resource book. Denver: Kempe Children's Center, University of Colorado School of Medicine.

Caliso, J. A., \& Milner, J. S. (1992). Childhood history of abuse and child abuse screening. Child Abuse \& Neglect, 16(5), 647-659.

Chamrathrithirong, A., \& Dejong, G. (1999). The quality-of-life consequences of internal labor migration in Thailand. Journal of the National Research Council of Thailand, 31, 79-104.

Chamratrithirong, A., Archavanakul, K., Richter, K., Guest, P., Thongthai, V., Boonchlaksri, W., et al. (1995). National migration survey of Thailand. Thailand: Institute of Population and Social Research.

Cicchetti, D., \& Toth, S. L. (1995). A developmental psychopathology perspective on child abuse and neglect. Journal of the American Academy of Child and Adolescent Psychiatry, 34(5), 541-65.
Coohey, C. (1996). Child maltreatment: testing the social isolation hypothesis. Child Abuse \& Neglect, 20(3), 241-54.

Dettlaff, A. J., Earner, I., \& Phillips, S. D. (2009). Latino children of immigrants in the child welfare system: prevalence, characteristics, and risk. Children and Youth Services Review, 31(7), 775-783.

Dong, M., Anda, R., Felitti, V., Williamson, D., Dube, S., Brown, D., et al. (2005). Childhood residential mobility and multiple health risks during adolescence and adulthood. Archives of Pediatrics \& Adolescent Medicine, 159(1104-1110).

Earner, I. (2007). Immigrant families and public child welfare: barriers to services and approaches for change. Child Welfare, 86(4), 63-91.

Elmer, E., \& Gregg, G. (1967). Developmental characteristics of abused children. Pediatrics, 40, 98-102.

Felitti, V., Anda, R., Nordenberg, D., Williamson, D., Spitz, A., Edwards, V., et al. (1998). Relationship of childhood abuse and household dysfunction to many of the leading causes of death in adults. The Adverse Childhood Experiences (ACE) Study. American Journal of Preventive Medicine, 14(4), 245-58.

Gracia, E., \& Musitu, G. (2003). Social isolation from communities and child maltreatment: a cross-cultural comparison. Child Abuse \& Neglect, 27(2), 153-68.

Guest, P. (2003). Bridging the gap: internal migration in Asia. Bangkok: Population Council.

Hadi, A. (2000). Child abuse among working children in rural Bangladesh: prevalence and determinants. Public Health, 114 (5), 380-4

Isaranurug, S., Nitirat, P., Chauytong, P., \& Wongarsa, C. (2001). Factors relating to the aggressive behavior of primary caregiver toward a child. Journal of the Medical Association of Thailand, 84(10), 1481-9.

Isaranurug, S., Chansatitporn, N., Auewattana, P., \& Wongarsa, C. (2002). Violence against children by parents. Journal of the Medical Association of Thailand, 85(8), 875-80.

Jirapramukpitak, T., Prince, M., \& Harpham, T. (2005). The experience of abuse and mental health in the young Thai population. A preliminary survey. Social Psychiatry and Psychiatric Epidemiology, 40(12), 955-63.

Kawachi, I., Kennedy, B. P., Lochner, K., \& Prothrow-Stith, D. (1997). Social capital, income inequality, and mortality. American Journal of Public Health, 87(9), 1491-8.

Kish, L. (1965). Survey sampling. London: Wiley.

Klevens, J., Bayon, M. C., \& Sierra, M. (2000). Risk factors and context of men who physically abuse in Bogota, Colombia. Child Abuse \& Neglect, 24(3), 323-32.

Kugel, C., Retzlaff, C., Hopfer, S., Lawson, D. M., Daley, E., Drewes, C., et al. (2009). Familias con Voz: Community survey results from an Intimate Partner Violence (IPV) prevention project with migrant workers. Journal of Family Violence, 24(8), 649-660.

Larson, O. W., Doris, J., \& Alvarez, W. F. (1987). Child maltreatment among U.S. east coast migrant farm workers. Child Abuse \& Neglect, 11(2), 281-291.

Larson, O. W., 3rd, Doris, J., \& Alvarez, W. F. (1990). Migrants and maltreatment: comparative evidence from central register data. Child Abuse \& Neglect, 14(3), 375-85.

McGee, T. G. (1991). The emergence of desakota region in Asia: Expanding a hypothesis. Honolulu: University of Hawaii.

Nathalang, S. (2000). Rangsit in transition: urbanisation and cultural adaptation in central Thailand. The Chao Phraya Delta: Historical Development, Dynamics and Challenges of Thailand's Rice Bowl. Bangkok: Kasetsart University.

Pinheiro, P. (2006). Report of the independent expert for the United Nations study on violence against children. Geneva: United Nations.

Putnam, R. D. (1995). Bowling alone: America's declining social capital. Journal of Democracy, 6, 65-78. 
Runyan, D. K., Hunter, W. M., Socolar, R. R., Amaya-Jackson, L., English, D., Landsverk, J., et al. (1998). Children who prosper in unfavorable environments: the relationship to social capital. Pediatrics, 101(1 Pt 1), 12-8.

Sampson, R., \& Laub, J. (1995). Crime in the making: pathways and turning points to life. Cambridge: Harvard University Press.

Sampson, R. J., Raudenbush, S. W., \& Earls, F. (1997). Neighborhoods and violent crime: a multilevel study of collective efficacy. Science, 277(5328), 918-24.

Segal, U. A., \& Mayadas, N. S. (2005). Assessment of issues facing immigrant and refugee families. Child Welfare, 84(5), 563-583.

Soubhi, H., Raina, P., \& Kohen, D. (2004). Neighborhood, family, and child predictors of childhood injury in Canada. American Journal of Health Behavior, 28(5), 397-409.

Straus, M. A. (1979). Measuring intrafamily conflict and violence: the Conflict Tactics (CT) scales. Journal of Marriage \& the Family, 41(1), 75-88.

Straus, M. A., \& Hamby, S. L. (1997). Measuring physical and psychological maltreatment of children with the Conflict Tactics Scales. In G. K. Kantor \& J. L. Jasinski (Eds.), Out of darkness:
Contemporary perspectives on family violence (pp. 119-135). Thousand Oaks: Sage.

Straus, M. A., Hamby, S. L., Finkelhor, D., Moore, D. W., \& Runyan, D. (1998). Identification of child maltreatment with the ParentChild Conflict Tactics Scales: development and psychometric data for a national sample of American parents. Child Abuse \& Neglect, 22(4), 249-70.

United Nations Statistics Division (2000). UNESCO statistics report. Geneva.

WHO. (1999). Report of the consultation on child abuse prevention, 29-31 March 1999. Geneva: World Health Organization.

WHO. (2002). World report on violence and health. Geneva: World Health Organization.

World Bank. (1998). The initiative on defining, monitoring and measuring social capital: overview and program description. Washington: The World Bank.

Yoddumneun-Attig, B. (2002). Kanchanaburi Project. from http:// www.mahidol.ac.th/mahidol/pr/IndividualEng2001.pdf.

Zolotor, A. J., \& Runyan, D. K. (2006). Social capital, family violence, and neglect. Pediatrics, 117(6), e1124-31. 